\title{
Emailing System with Elevated Safeguard Procedures
}

\author{
S.Sangeetha, G.Kavitha, C.Anuradha, S.Pothumani
}

\begin{abstract}
Email, e mail, or e mail, is considered probably the most normally employed solution on the net. Throughout the years, email has developed dramatically, appearing in view that essential process of interaction. Nevertheless as soon as maltreat, the interaction predicated on electronic mail might lift some downsides and in addition detrimental for your organizational security, privateness and know-how confidentiality. There is surely not enough a scheme by which person would in all probability get authenticate, in view that now no manipulate is had with the aid of us on the communications arriving at our mailbox. Due to the fact that these severe challenges, the value of securing age that's soft expertise is apparent and primary. There is undoubtedly a process to preserve our expertise safeguarded a nd locked from any person nevertheless the e-mail that is initial is by means of general public key of the receiver. When have the key that is basic public Sender encrypts the e mail accessory and promises the message to your receiver. The receiver $h$ at the same time the private key related to most of the people-confidential key set which can also be detailed for decrypting the message. The receiver decrypts the components and decodes the message put up aided with the aid of the attachment consequently getting the attachments which can be fashioned. Consequently in this precise procedure protection is offered to mail content.MSA Encrypti utilizing the technique called as mail content encryption. Within our assignment the approach will likely be utilized by means of us uneven key cryptography for the encryption of electronic mail articles. Passwords directed on the records are quite often stored at host phase simply but there would be means that is 1/3 o shop our account password on our platform where we utilize electronic mail individual on \&Decrypti on of procedure frequently. Today android becomes a very means which are widespread utilze the web hence we're capable to make use of password kept on our our bodies or cellular to gain access to o ur electronic mail account.
\end{abstract}

.Keywords: e mail, security, privateness, Cryptography, Passwords, Server, Android Os, information Confidentiality, Integrity.

\section{INTRODUCTION}

Email email, or e-mail, is regarded the most $\mathrm{f}$ requently utilizedanswer on the net. By way of the complete years, e-mail has developed dramatically, developing as soon as the predominant way of interplay. Inside our base paper recounted that, a knowledge drip would be the deliberate or unintentional launch of protected expertise to a breeding floor that's unlawful. O ther phrases with this event

Revised Manuscript Received on July 22, 2019.

S.Sangeetha, Assistant Professor, Department of CSE, Bharath Institute of Higher Education and Research

G.Kavitha, Assistant Professor, Department of CSE, Bharath Institute of Higher Education and Research

C. Anuradha, Assistant Professor, Department of CSE, Bharath Institute of Higher Education and Research

S. Pothumani, Assistant Professor, Department of CSE, Bharath Institute of Higher Education and Research encompass information that is accidental, know-how breach and additionally knowledge spill Definition "an information drip is a security occasion by which painful and sensitive, included or confidential knowledge is copied, sent, noticeable, taken or utilized via a individual unauthorized to accomplish so". Integrity and confidentiality of knowledge or data is guaranteed by means of a knowledge things being fake [1-5]. Then we might offer importance of safeguard of knowledge as a substitute making functioning of verbal exchange more problematic each time we that terrifies them expertise alteration o $\mathrm{r}$ change. Inside of our proposed method there is absolutely solution for effortless and efficient strategy to relocating expertise with the aid of utilising uneven cryptography that's key [6-11].

The email components are encrypted through using uneven key cryptography algorithm in this web utility. Sender before delivering the message to your receiver, demand theemail known as e-mail has developed somewhat via the complete years, rising a s the major approach of interaction [12-15]. On the other hand when misused, e mail headquartered interplay may raise drawbacks which can be distinct.

- A message that's unsecure risk to at least one's organizational security, on account that it provides the personal data about exact organization.

- A message that is unsecure moreover dangerous for one's

privateness, considering the fact that it is unsecure form the social gathering hacker that's third.

- A message that is unsecure possibly not preserve the knowledge confidentiality, as no encryption is completed related to the e mail.

- With utilising unsecured mail you will in finding probabilities of painful and touchy expertise leakage without any danger for monitoring.

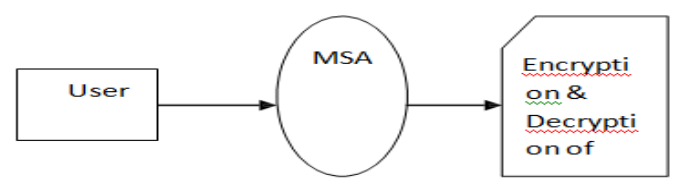

Figure 1: Basic Structure of Email System Application

A steganography a pplication used to be created to reinforce know-how that is private safeguard in this research [16-19]. This software is meant to provide an much more dependable manner of interaction for e-mails which participate in an role that is very fundamental individual $\mathrm{d}$ ata switch. Consequently, Steganography, w hich is amongst the interplaymethods being hiding is used. And steganography that may be current are analyzed and a contemporary application used to be developed to be utilized for individual expertise protection. Subsequently, their application had been placed on an mail conversation.[20-26]] that's digital.

Published By:

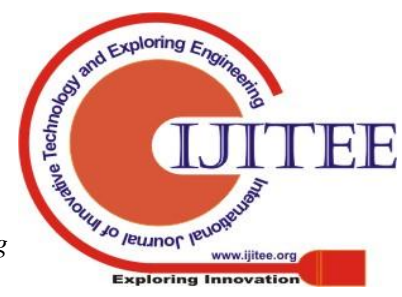




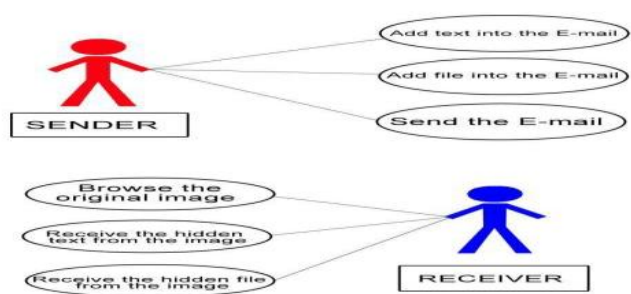

Figure 2: usage example diagram of application.

Due to the fact there may be big escalation in use of cloud computing, securing customers e-mails can be an challenge that maintains growing. This paper rankings the boundaries, privacy, weaknesses, varying legislations of cloud situated e-mails, and simply how to mitigate such to gift in charge and cloud that's included electronic mail options for users and companies. We advocate a framework that is manufacturer new support protection of cloud based digital mails: wise Cloud centered electronic mail E ncryption and Decryption method (ICLEEDS). The purpose is to encrypt content material of e-mail mail communications from users' mail area earlier than being delivered. The intelligent laptop encryption that is studying particularly helps to look after customers in opposition to e mail interception, re-construction, phishing attacks, relaying of past messages, spoofing, eavesdropping and provide advanced stage of privacy.[27-32].

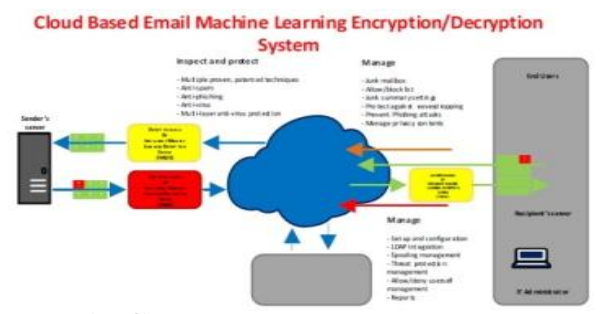

Figure 3: Cloud heAdQuARTERED ELECTRONIC MAIL M ACHINE ENCRYPTION/DECRYPTION SYSTEM THAT'S LEARNING

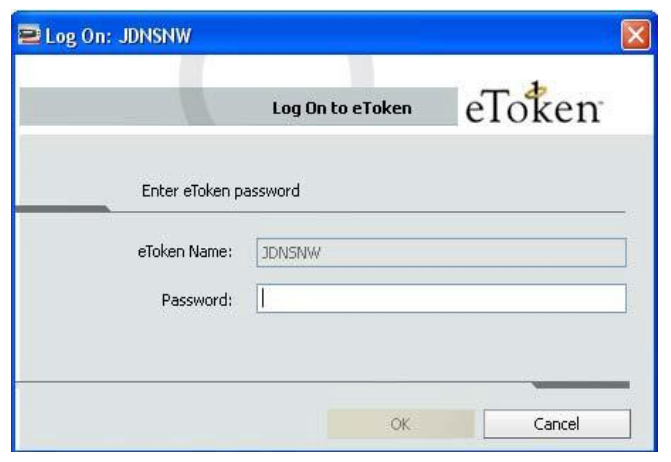

\section{FIGURE 4:TOKEN BASED E-MAIL SYSTEM}

The principal issues t cap common emails endure are knowledge commencing verification and integrity that's connectionless from privacy. Which way it is not tampered with that it can be quite hard with the ordinary e mail to exhibit that the transmitter particularly composed the message, or? Many humans provide mail in two approach with a interface that is internet-established Yahoo! Or Hotmail, or with an "electronic mail client" approach like Outlook or Eudora. Correct right here we will be talking about about a system to comfortable electronic mail messages on a MS Outlook varieties of environment. To gift e-mail defense in a MS Outlook forms of environment. The points which can also be primary privateness, Integrity, Authentication, Non-Repudiation and Availability have got to be used underneath the security mind. [37]

\section{LITERATURE ASSESSMENT}

After speaking about about introduction of safety provided to thetoday e-mail s ystems international. In this phase we're briefing about literature s urvey within the options being different by means of literatures/authors.

In paper [38] 2014 writers have actually analysed regarding the safeguard furnished in the direction of the mail that's electronic with the support of age - token.Trouble mentioned they will have pointed out about security into theMS-Outlook sort of atmosphere.

Proposed answer writers have without a doubt proposed options in following way.

Confidentiality: The privacy or privacy trouble of the application type is addressed via utilizing a 448 bit key algorithm that's symmetric. It is a ambitious block cipher which i s 64 bit block cipher and attaining 32 bit size that's key. Integrity: author claims that with the support of SHA-1 and RSA they may be able to have the potential to make know-how better and increase the integrity closer to the information to be certain nobody must be in a position to make modifications closer to the information with a purpose to be switch that is tobe the letter network.

Quandary: they've probably now not caused individual verification which can be ordinarily a danger that is important e mail method protection.

In paper [39] 2013 Authors have do evaluation that is ne providing safety towards the email accent articles i sort of steganography. Based on the writers steganograpy might be the process that is most worthy to $\mathrm{h}$ ide and present protection to concealed expertise.

Challenge mentioned:they have certainly talked about regarding the problem of safety and privateness happened in the event of some understanding that is external to be delivered on the internet. Based on writers we have absolutely to present the protection that's extra the components related to electronic mail approach.

Proposed solution: From authors point of view steganography is the apparatus by means of which we can present safeguard in the direction of the email accessories. Then s ecurity can be used however every person will comes to grasp that right here is the knowledge which incredibly guaranteed each time we strive to utilize nearly any variety of s ecurity apparatus. However no body will recognize that that is a secured knowledge travelling over community at any time when we make use of steganography.

Trouble: Steganography is the process during which information is hide within one more get knowledge 1 ike photograph. But due $t$ their $r$ esultant file produced is of enormous dimension. They've developed and labored whatever with numerous complexities

In paper [3] 2013 Authors have without a doubt mentioned aided via the weaknesses and bounds in cloud centered electronic mail procedureand proposed a mission safety that offers cloud established e-mailprotection.Predicament talked about: cloud could be the system situated server having abilities of saving and expertise which can be gaining access to programs. Cloud 
supports saving laptop software, firmware and so forth. Issues like relieving of knowledge space for storing, collaboration of quite a lot of documents over cloud. Emails conserved on cloud fairly conserved in numerous international locations having cyber that's vastly different and legal guidelines. Some cloud that's current solutions and apps are:

- $\quad$ Bing Apps [6]: (comprising Gmail, Bing Calendar, Bing doctors, as good as other web applications) present familiar, person pleasant merchandise for enterprise settings.

- IBM LotusLiveiNotes[7]: This answer is IBM's very first actual foray right into a mass-market answer that is cloud-founded.

- Restrictions: they've not included the percentage of any kind or forms of assault do ne $b$ y hacker or intruder. Like mail bomb attack, passive assault and and many others.

In paper [4] 2013 writers have clearly targeted upon the unsolvedhindrance of getting a majority of undesired communications travelling our inbox which we called as unsolicited mail. Unsolicited mail might be the mail transferring over internetwork growing bourdon o ver group on the grounds that well as mailbox of man or woman additionally. Despite the readiness of at present's electronic mail infrastructure, it's difficult to assurance the authenticity of a sender target for inbound mails. This shortcoming is employed via spammers to bypass spam that's current programs and additionally poses a safety danger to customers. Given that of this a enormous part that is enormous of e-mails today are delivered from botnets with forged s ender details.

Difficulty pointed out: writers evaluation say that the progress that is explosive the unsolicited electronic mail (spam) in the last decade has managed to make it not possible for e-mail communications to function with out spam safety. Till now additionally spam is situation that's unsolved [40, 41].

\section{PROPOSED SOLUTIONS}

Authors believes that making use of the transmitter and $r$ eceiver's identification w age can stops the blem that is pro ofnsolicited mails to arrive our mailbox. E mail transmitter verification mechanisms allow receivers to inform aside forgeries from right away legitimate communications. Author makes use of Sender policy Framework (SPF) and area Keys recognized Mail (DKIM) protocols as a man or woman verification protocol for attention.

Hindrance: author have certainly mentioned and implanted a system with having an apparatus that is mighty regarding the man or woman who's supplying mails however there is however no any solutions which provide the s ecurity to expertise carried by means of e-mails.

In paper [5] 2011 author have inked survey on mixture of two encryption schemes to produce knowledge better while moving over group. Based on paper with the aid of writer he acknowledged evolved E ncryption common (AES) and Elliptic Curve Cryptosystems (ECC) stands out as the two most in most cases utilized symmetric and encryption that's asymmetric. And hence then information might be extra assured if we make combination of each them.

Hindrance talked about: From author factor of view there is surely nothing any gadget that works well in market to supply safeguard to the knowledge .So we want a risklessencryption algorithm to support make encryption.
Asymmetric algorithms are tricky along with other system don't seem to be strongbased on writer.

Proposed answer: writer giving us a relief that's helpful make our knowledge safer in following means. AES is the symmetrical encryption algorithm and ECC (Elliptic Curve Cryptosystems) is the circulation scheme that's key.

Through mixture of this formulation we might encrypt information by AES and distribute that symmetric key by using utilizing ECC key circulation apparatus.

Limits: symmetric encryption that's key with a couple of inconveniency which might be like encryption and decryption by way of making use of o nlyo ne key. Lack of key brings loss in expertise. So we must use an extra procedure like ECC to deal with pointers over community when you consider that of which it gets to be more system that's tricky.

\section{REFERENCES}

1. Kaliyamurthie, Kumarave A., RangarajanK.,Algorithm for automaton specification for exploring dynamic labyrinths,Indian Journal of Science and Technology, V-6,I-SUPPL5,PP-4554-4559,Y-2013

2. P. Kavitha, S. Prabakaran "A Novel Hybrid Segmentation Method with Particle Swarm Optimization and Fuzzy C-Mean Based On Partitioning the Image for Detecting Lung Cancer" International Journal of Engineering and Advanced Technology (IJEAT) ISSN: 2249-8958, Volume-8 Issue-5, June 2019

3. Kumaravel A., MeeteiO.N.,An application of non-uniform cellular automata for efficient cryptography,2013 IEEE Conference on Information and Communication Technologies, ICT 2013,V-,I-,PP-1200-1205,Y-2013

4. Kumarave A., RangarajanK.,Routingalogrithm over semi-regular tessellations,2013 IEEE Conference on Information and Communication Technologies, ICT 2013,V-,I-,PP-1180-1184,Y-2013

5. P. Kavitha, S. Prabakaran "Designing a Feature Vector for Statistical Texture Analysis of Brain Tumor" International Journal of Engineering and Advanced Technology (IJEAT) ISSN: 2249-8958, Volume-8 Issue-5, June 2019

6. Dutta P., Kumaravel A.,A novel approach to trust based identification of leaders in social networks, Indian Journal of Science and Technology,V-9,I-10,PP--,Y-2016

7. Kumaravel A., DuttaP.,Application of Pca for context selection for collaborative filtering,Middle - East Journal of Scientific Research,V-20,I-1,PP-88-93,Y-2014

8. Kumaravel A., RangarajanK.,Constructing an automaton for exploring dynamic labyrinths,2012 International Conference on Radar, Communication and Computing, ICRCC 2012,V-,I-,PP-161-165,Y-2012

9. P. Kavitha, S. Prabakaran "Adaptive Bilateral Filter for Multi-Resolution in Brain Tumor Recognition” International Journal of Innovative Technology and Exploring Engineering (IJITEE) ISSN: 2278-3075, Volume-8 Issue-8 June, 2019

10. KumaravelA.,Comparison of two multi-classification approaches for detecting network attacks, World Applied Sciences Journal,V-27,I-11,PP-1461-1465,Y-2013

11. Tariq J., KumaravelA.,Construction of cellular automata over hexagonal and triangular tessellations for path planning of multi-robots,2016 IEEE International Conference on Computational Intelligence and Computing Research, ICCIC 2016,V-,I-,PP--,Y-2017

12. Sudha M., KumaravelA.,Analysis and measurement of wave guides using poissonmethod,Indonesian Journal of Electrical Engineering and Computer 
Science,V-8,I-2,PP-546-548,Y-2017

13. Ayyappan G., Nalini C., KumaravelA.,Various approaches of knowledge transfer in academic social network,InternationalJournal of Engineering and Technology, V-,I-,PP-2791-2794,Y-2017

14. Kaliyamurthie, K.P., Sivaraman, K., Ramesh, S. Imposing patient data privacy in wireless medical sensor networks through homomorphic cryptosystems 2016, Journal of Chemical and Pharmaceutical Sciences 92.

15. Kaliyamurthie, K.P., Balasubramanian, P.C. An approach to multi secure to historical malformed documents using integer ripple transfiguration 2016 Journal of Chemical and Pharmaceutical Sciences 92.

16. A.Sangeetha,C.Nalini,"Semantic Ranking based on keywords extractions in the web", International Journal of Engineering \& Technology, 7 (2.6) (2018) 290-292

17. S.V.GayathiriDevi,C.Nalini,N.Kumar,"An efficient software verification using multi-layered software verification tool "International Journal of Engineering \& Technology, 7(2.21)2018 454-457

18. C.Nalini,ShwtambariKharabe,"A Comparative Study On Different Techniques Used For Finger - Vein Authentication", International Journal Of Pure And Applied Mathematics, Volume 116 No. 8 2017, 327-333, Issn: 1314-3395

19. M.S. Vivekanandan and Dr. C. Rajabhushanam, "Enabling Privacy Protection and Content Assurance in Geo-Social Networks", International Journal of Innovative Research in Management, Engineering and Technology, Vol 3, Issue 4, pp. 49-55, April 2018.

20. Dr. C. Rajabhushanam, V. Karthik, and G. Vivek, "Elasticity in Cloud Computing", International Journal of Innovative Research in Management, Engineering and Technology, Vol 3, Issue 4, pp. 104-111, April 2018.

21. K. Rangaswamy and Dr. C. Rajabhushanamc, "CCN-Based Congestion Control Mechanism In Dynamic Networks", International Journal of Innovative Research in Management, Engineering and Technology, Vol 3, Issue 4, pp. 117-119, April 2018.

22. Kavitha, R., Nedunchelian, R., "Domain-specific Search engine optimization using healthcare ontology and a neural network backpropagation approach", 2017, Research Journal of Biotechnology, Special Issue 2:157-166

23. Kavitha, G., Kavitha, R., "An analysis to improve throughput of high-power hubs in mobile ad hoc network", 2016, Journal of Chemical and Pharmaceutical Sciences, Vol-9, Issue-2: 361-363

24. Kavitha, G., Kavitha, R., "Dipping interference to supplement throughput in MANET" , 2016, Journal of Chemical and Pharmaceutical Sciences, Vol-9, Issue-2: 357-360

25. Michael, G., Chandrasekar, A.,'Leader election based malicious detection and response system in MANET using mechanism design approach", Journal of Chemical and Pharmaceutical Sciences(JCPS) Volume 9 Issue 2, April - June 2016 .

26. Michael, G., Chandrasekar, A.,"Modeling of detection of camouflaging worm using epidemic dynamic model and power spectral density", Journal of Chemical and Pharmaceutical Sciences(JCPS) Volume 9 Issue 2, April - June 2016.

27. Pothumani, S., Sriram, M., Sridhar, J., Arul Selvan, G., Secure mobile agents communication on intranet,Journal of Chemical and Pharmaceutical Sciences, volume 9, Issue 3, Pg No S32-S35, 2016

28. Pothumani, S., Sriram, M., Sridhar, Various schemes for database encryption-a survey, Journal of Chemical and Pharmaceutical Sciences, volume 9, Issue 3, Pg NoS103-S106, 2016

29. Pothumani, S., Sriram, M., Sridhar, A novel economic framework for cloud and grid computing, Journal of Chemical and Pharmaceutical Sciences, volume 9, Issue 3, Pg No S29-S31, 2016
30. Priya, N., Sridhar, J., Sriram, M. "Ecommerce Transaction Security Challenges and Prevention Methods- New Approach" 2016 ,Journal of Chemical and Pharmaceutical Sciences, JCPS Volume 9 Issue 3.page no:S66-S68

31. Priya, N.,Sridhar,J.,Sriram, M."Vehicular cloud computing security issues and solutions" Journal of Chemical and Pharmaceutical Sciences(JCPS) Volume 9 Issue 2, April - June 2016

32. Priya, N., Sridhar, J., Sriram, M. "Mobile large data storage security in cloud computing environment-a new approach" JCPS Volume 9 Issue 2. April - June 2016

33. Anuradha.C, Khanna.V, "Improving network performance and security in WSN using decentralized hypothesis testing "Journal of Chemical and Pharmaceutical Sciences(JCPS) Volume 9 Issue 2, April - June 2016.

34. Anuradha.C, Khanna.V, "A novel gsm based control for e-devices" Journal of Chemical and Pharmaceutical Sciences(JCPS) Volume 9 Issue 2, April - June 2016.

35. Anuradha.C, Khanna.V, "Secured privacy preserving sharing and data integration in mobile web environments " Journal of Chemical and Pharmaceutical Sciences(JCPS) Volume 9 Issue 2, April - June 2016.

36. Sundarraj, B., Kaliyamurthie, K.P. Social network analysis for decisive the ultimate classification from the ensemble to boost accuracy rates 2016 International Journal of Pharmacy and Technology 8

37. Sundarraj, B., Kaliyamurthie, K.P. A content-based spam filtering approach victimisation artificial neural networks 2016 International Journal of Pharmacy and Technology 8 3.

38. Sundarraj, B., Kaliyamurthie, K.P. Remote sensing imaging for satellite image segmentation 2016 International Journal of Pharmacy and Technology 83.

39. Sivaraman, K., Senthil, M. Intuitive driver proxy control using artificial intelligence 2016 International Journal of Pharmacy and Technology 84.

40. Sivaraman, K., Kaliyamurthie, K.P. Cloud computing in mobile technology 2016 Journal of Chemical and Pharmaceutical Sciences 92.

41. Sivaraman, K., Khanna, V. Implementation of an extension for browser to detect vulnerable elements on web pages and avoid click jacking 2016 Journal of Chemical and Pharmaceutical Sciences 92.

\section{AUTHORS PROFILE}

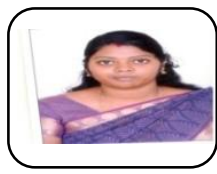

S.Sangeetha profile which contains their education details, their publications, research work, membership, achievements, with photo that will be maximum 200-400 words.

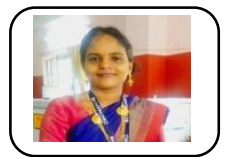

G.Kavitha profile which contains their education details, their publications, research work, membership, achievements, with photo that will be maximum 200-400 words

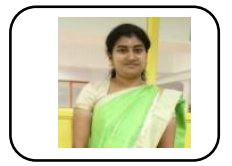

C.Anuradha profile which contains their education details, their publications, research work, membership, achievements, with photo that will be maximum 200-400 words.

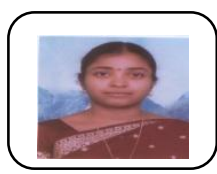

S.Pothumani profile which contains thei education details, their publications, research work, membership, achievements, with photo that will be maximum 200-400 words. 